Lepr Rev (1999) 70, 472-479

\title{
Report of the national leprosy elimination campaign (NLEC) of Bangladesh, 1999
}

\author{
JALAL UDDIN AHMED \\ National Leprosy Elimination Programme, Leprosy Hospital \\ Compound, Mohakhali, Dhaka-1212, Bangladesh
}

Accepted for publication 9 September 1999

\begin{abstract}
Summary A national leprosy elimination campaign (NLEC) was implemented country-wide in all the 64 districts of Bangladesh for 6 days from 7 to 12 February 1999. The campaign was jointly funded by the Government of Bangladesh (GOB)/ World Bank (US\$250,000) and the remaining US\$381,000 was provided by other international non-governmental organizations (NGOs). A total of 44,400 health workers and community volunteers were directly involved in the campaign. In all, 60,878 suspected leprosy cases were identified during the campaign, of whom 31,433 were examined and 2435 were confirmed as leprosy cases. The remaining suspects are expected to be examined within the next 2 months. Details of the new cases detected are given in Table 8. The impact of NLEC has been significant, the number of cases detected during NLEC being 20\% of the annual case detection in 1998. About $52 \%$ of the total population were directly contacted through a rapid house-tohouse survey and over $90 \%$ of the population was targeted through extensive use of electronic/print media and various information, education and communication (IEC) activities.
\end{abstract}

\section{Main objectives}

The overall objective was to support the achievement of the goal of elimination of leprosy as a public health problem by the year 2000 . The main objectives were:

1. To create nationwide awareness of leprosy.

2. To detect as many of the remaining hidden cases in the country (estimated to be 30,000 at the end of 1998).

3. To provide MDT to all detected cases and cure them.

4. To increase the capacity at local level to promote case detection and support MDT services.

This study was carried out with the assistance of Dr Shaikh A. Shahed Hossain and Dr Kazi Belayet Ali. 


\section{Activities}

PRE-CAMPAIGN

1. Advocacy meeting at central/division/district and thana (health complex) level.

2. Capacity building: orientation of health workers, NGO workers and volunteers.

3. Media workshop: 2-day workshop at Dhaka.

4. IEC activities.

\section{CAMPAIGN DAYS}

1. Publicity by public address systems.

2. Contact with religious leaders.

3. Group meetings at villages and schools.

4. Rapid photo survey from house to house.

5. Discourse in mosques/churches/temples.

\section{POST-CAMPAIGN}

1. Collection and compilation of reports.

2. Assessment of short-term impact of NLEC through sample survey.

3. Continuation of IEC activities.

\section{Pre-campaign activities}

1. Donor's meeting on 5 February 1998. The preparatory phase commenced with the meeting of officials from government, WHO and international NGOs. At this meeting, the preliminary draft of the NLEC plan of action and a provisional budget was approved.

2. Preparatory activities:

- Preparation of funding allocation for different levels of activity.

- Development and printing of IEC materials.

- Development, printing and distribution of guidelines in Bangla on NLEC implementation to district/thana managers and health workers/volunteers.

- Selection and 1-day orientation of government health workers, NGO workers, community volunteers and city corporation and urban volunteers.

3. One-day orientation on NLEC of health managers at central, division and district levels.

4. Advocacy meetings at central, division, district and thana level. At least one meeting was held in each area. The participants were heads of government offices/teachers/media representatives/medical professionals/NGO members/religious leaders/representatives from women's organizations and other community leaders (Tables 1 and 2). Countrywide total participants were about 28,900 at all levels.

5. Media workshop: a 2-day workshop was held in Dhaka with the participation of 46 journalists from different newspapers, local and foreign, representatives from TV and radio and government officials. The workshop was jointly sponsored by GOB, WHO, International Leprosy Union (ILU), Damien Foundation and Lepra UK. A team of resource personnel, including four from abroad, facilitated the various sessions. The Honourable Minister for Health and Family Welfare and the Honourable State Minister for 
Table 1. Capacity building at local level

\begin{tabular}{|c|c|c|c|c|}
\hline Categories of worker & Type of training & Resource personnel & Place of training & Duration \\
\hline GOB Health Assistants (HA) & $\begin{array}{l}\text { Orientation on cause, early signs, curability, } \\
\text { availability of free treatment and on } \\
\text { referral services. } \\
\text { Also on preparation of reports }\end{array}$ & $\begin{array}{l}\text { Local Health } \\
\text { Managers/Medical } \\
\text { Officer in Charge }\end{array}$ & Thana Health Complex (THC) & 1 day \\
\hline GOB Family Welfare Workers (FWA) & Same as above & Same as above & Same as above & 1 day \\
\hline NGO workers & Same as above & $\begin{array}{l}\text { Same as above } \\
+ \text { NGO Supervisors }\end{array}$ & $\begin{array}{l}\text { In THCs and NGO-run } \\
\text { MDT centres }\end{array}$ & 1 day \\
\hline Community Volunteers & Same as above & Same as above & Same as above & 1 day \\
\hline City Corporation Workers & Same as above & Same as above & City Corporation & 1 day \\
\hline Urban Health Workers & Same as above & Same as above & $\begin{array}{l}\text { City Corporation }+ \\
\text { NGO centres }\end{array}$ & 1 day \\
\hline
\end{tabular}


Table 2. Breakdown of workers who participated in NLEC

\begin{tabular}{llrl}
\hline SI no. & $\quad$ Categories of workers & Number & Gender \\
\hline 1 & GOB Health Assistants & 13,398 & $95 \%$ male \\
2 & GOB Family Welfare Workers & 13,425 & All female \\
3 & NGO workers & 3143 & $90 \%$ male \\
4 & Community volunteers & 13,398 & $60 \%$ male/ \\
& & & $40 \%$ female \\
5 & City Corporation Workers & 677 & Male/female \\
6 & Urban Health Workers & 359 & Male/female \\
Total & & 44,400 & \\
& & & \\
\hline
\end{tabular}

Information were chief guests in two sessions, respectively. This workshop had a great impact on NLEC and ensured wide media coverage before, during and after the campaign days.

6. Other IEC activities included pasting of posters, distribution of leaflets, stickers on vehicles and other important public places, banners for road decoration and broadcasting radio jingles and TV spots on, during and before NLEC days (Table 3).

\section{Campaign activities}

The daily campaign activities were as follows (Table 4):

Day 1: (a) Publicity through microphone, in all the 135,000 wards of the country, covering all villages within the ward. (Thanas are subdivided into unions and each union has three wards.)

(b) Imams of local mosques and priests from local churches and temples were contacted and motivated to participate and support the NLEC.

Day 2: Group meetings in at least two villages and two schools per team of worker/ volunteer.

Day 3: Group meetings in at least two additional villages and two additional schools per team of worker/volunteer.

Table 3. IEC materials used during NLEC

\begin{tabular}{llcc}
\hline SI no. & Categories/items & Types & Number/duration \\
\hline 1 & Posters & 5 & $11,100 *$ \\
2 & Leaflets & 4 & $2,147,500$ \\
3 & Stickers & 1 & 20,000 \\
4 & Banners & 3 & 100 (4 City Corporations) \\
5 & Radio jingles & 2 & 1 month \\
6 & TV spots & 2 & 1 month \\
\hline
\end{tabular}

*The number of posters printed was small because previous experience during LEC in 20 districts conducted in 1997-1998 indicated that posters have very little impact in Bangladesh. 
Table 4. Summary of coverage during campaign days

\begin{tabular}{lllll}
\hline SI no. & \multicolumn{1}{c}{ Activities } & Total in country & NLEC coverage & \multicolumn{1}{c}{ Remarks } \\
\hline 1 & $\begin{array}{l}\text { Rapid photo survey: } \\
\text { population contacted }\end{array}$ & 122 million & $\begin{array}{l}63 \text { million } \\
\text { (about } 52 \%)\end{array}$ & $\begin{array}{l}\text { Direct contact during house- } \\
\text { to-house rapid survey } \\
\text { At least two meetings in each } \\
\text { village }\end{array}$ \\
2 & Group meetings at villages & About 70,000 & $60,924(87 \%)$ & One meeting in each school \\
3 & Group meetings in schools & NA & About 44,216 & $\begin{array}{l}\text { Oncluding priests and } \\
\text { preachers }\end{array}$ \\
\hline
\end{tabular}

Day 4: Rapid photo survey covering all households in at least two villages per team of worker/volunteer.

Day 5: Rapid photo survey covering all households in an additional two villages per team of worker/volunteer.

Day 6: Friday-discourse on leprosy in about 50,000 mosques in the country.

Saturday and Sunday-discourse on leprosy in local temples and churches.

Several teams of supervisors (Table 5) participated in monitoring and supervision of NLEC activities during campaign days.

\section{Post-NLEC activities}

Post-NLEC activities included collection and summarization of results, survey to assess the short-term impact of NLEC and continuation of IEC activities through print and electronic media in order to keep up the intensity of leprosy elimination activities.

A survey was undertaken by the National Programme with the participation of representatives from WHO consultants, NGOs and government personnel in 18 districts (34 thanas) on a random sample basis. The participating teams interviewed health workers and volunteers who were involved in NLEC, re-examined and validated the cases diagnosed during NLEC (25\%), spoke to community workers and health managers and assessed the activities performed. The population and area covered during survey are given in Table 6 .

Supplements on leprosy were published in 15 newspapers (10 Bangla and five English) and radio jingles and TV spots were broadcast continuously throughout the month of February 1999.

Table 5. Categories of supervisor at different levels

\begin{tabular}{llrl}
\hline SI no. & Level & Number & Organization \\
\hline 1 & Thana & 3547 & GOB + NGO \\
2 & District & 330 & GOB + NGO \\
3 & Central & 70 & GOB + NGO and international organizations \\
4 & Total & 3947 & (WHO HQ, Geneva/TLMI-UK, etc.) \\
\hline
\end{tabular}


Table 6. NLEC and survey coverage

\begin{tabular}{llccc}
\hline SI no. & \multicolumn{1}{c}{ Unit } & Total in country & NLEC coverage & Survey coverage \\
\hline 1 & District & 64 & 64 & $18(28 \%)$ \\
2 & City Corporations & 4 & 4 & $4(100 \%)$ \\
3 & Thanas & 460 & 460 & $34(7 \cdot 3 \%)$ \\
4 & Population & 122 million & $90 \%$ & $10 \%$ \\
\hline
\end{tabular}

\section{Main difficulties}

1. NLEC activities were partially hampered in some urban areas due to a call for a general strike by a political party for 3 days, from 9 to 11 February 1999. In such areas, the activities were continued on subsequent days.

2. In the absence of national consultants at the central and divisional level (their recruitment was delayed due to administrative reasons), there were some gaps in monitoring and supervision of various activities.

3. Co-ordination and communication difficulties in certain areas.

4. National Immunization Day mop-up operation at the same time in 21 thanas affected NLEC implementation in these thanas to some extent.

5. Delay in the release of funds (GOB/Sasakawa Memorial Health Foundation).

\section{What has been achieved?}

The results of the NLEC are shown in Tables 7-10.

\section{Plans for maintaining in the project/programme areas}

1. The health workers in the field, NGO workers involved and trained volunteers will:

- continue to refer suspected cases and patients.

- continue IEC activities (providing simple messages of curability, availability of leprosy treatment free of cost, etc., through field work, print and electronic media.

- contact survey of index cases.

- mass survey in the selected areas whenever necessary.

- other MDT activities (ensuring drug compliance, defaulter tracing, motivation of community leaders and others).

2. Routine MDT services available in all thanas (sub-districts) and other MDT centres throughout the country will be intensified under the new Health and Population Sector

Table 7. Suspected leprosy cases detected and cases confirmed

\begin{tabular}{lcccr}
\hline Suspected & Cases examined & Confirmed & PB including SLPB & MB \\
\hline 60,878 & 31,433 & 2435 & 1198 & 1237 \\
\hline
\end{tabular}


Table 8. Leprosy situation in Bangladesh before NLEC and in 1999 (first quarter)

\begin{tabular}{rcccccccr}
\hline Year & Population & P/R 10,000 & $\begin{array}{c}\text { New case } \\
\text { detection }\end{array}$ & MB\% & DGRII\% & Child\% & Self-reporting\% & $\begin{array}{c}\text { D/R } \\
100,000\end{array}$ \\
\hline 1996 & $115,123,899$ & $1 \cdot 16$ & 11,226 & 34 & $11 \cdot 28$ & $15 \cdot 80$ & 35 & $9 \cdot 75$ \\
1997 & $115,123,899$ & $1 \cdot 15$ & 11,320 & 35 & 11.73 & $15 \cdot 00$ & 37 & $9 \cdot 83$ \\
1998 & $122,114,456$ & $0 \cdot 86$ & 12,364 & 35 & 8.99 & $18 \cdot 3$ & 30 & $10 \cdot 12$ \\
1999 & $122,114,456$ & 0.94 & 4310 & 45 & $11 \cdot 11$ & $13 \cdot 50$ & 31 & $3 \cdot 61$ \\
\hline
\end{tabular}

Programmes (HPSP) adopted during the Fifth Five Years Financial Plan. Now the MDT services may even be extended up to the Community Clinics (one clinic for 6000 population planned.

3. Under line management of HPSP, all the above activities will be ensured, and regular monitoring and supervision will be strengthened.

4. Along with the regular orientation of Scout leaders and private practitioners, other IEC components of the activities will be strengthened, notably under the unified BCC (Behaviour Change Communication) component of HPSP.

5. Another short duration ( 2 weeks) LEC is proposed during 1999-2000 in selected areas of the country.

6. Another evaluation of the programme at the end of 1999 or beginning of 2000 by the programme management is actively under consideration.

\section{Plans for disseminating/publishing results}

1. The results of NLEC will be presented at the consultative meeting on Leprosy Elimination Campaigns to be held in Geneva on 14-15 July 1999.

2. Final results will be disseminated through line management to all Health and Family Planning components of HPSP and to all NGOs working in the leprosy field.

3. It is proposed to publish the experience of the nationwide campaign and subsequent survey to different national and international journals.

\section{Conclusions}

1. The number of new cases detected in the first quarter of 1999 is $42 \%$ higher compared with the first quarter of 1998. This increase can be largely attributed to NLEC.

Table 9. Details of new cases detected during NLEC

\begin{tabular}{|c|c|c|c|c|c|c|}
\hline Categories/organization & SLPB & PB & MB (\%) & Total & Gr II & Child (\%) \\
\hline GOB & 63 & 528 & $867(59 \cdot 5)$ & 1458 & $291(20 \cdot 0)$ & $143(10 \cdot 0)$ \\
\hline NGO & 106 & 501 & $370(37.8)$ & 977 & $109(11 \cdot 1)$ & $139(14 \cdot 2)$ \\
\hline Total & 169 & 1029 & $1237(50 \cdot 8)$ & 2435 & $400(16 \cdot 6)$ & $282(11.7)$ \\
\hline
\end{tabular}


Table 10. Comparative new case detection in first quarter of 1998 and 1999-10-21

\begin{tabular}{lrrrrrr}
\hline Period & SLPB & PB & MB & Total & Gr II & Child \\
\hline 1st quarter 1998 & 78 & 1943 & 999 & 3020 & 309 & 574 \\
1st quarter 1999 & 222 & 2160 & 1928 & 4310 & 479 & 582 \\
\hline
\end{tabular}

2. There is an increase of $17 \%$ in the PB cases detected and an increase in $93 \%$ in MB cases detected in the first quarter of 1999. This indicates that a substantial number of cases of consequence (MB) have been detected during NLEC.

3. The total number of cases and MB case percentage detected during NLEC were $53 \%$ and $59 \%$, respectively, of the total cases and $\mathrm{MB}$ cases detected during the first quarter of 1999.

4. The post-NLEC sample survey in 34 thanas indicated that $75 \%$ of the respondents were aware of NLEC activities. The major sources of information were television (43\%), microphones $(31 \%)$, radio $(23 \%)$, newspapers (8\%) and imams (5\%).

The 6-day NLEC was successfully implemented country-wide in Bangladesh from 7 to 12 February 1999. As expected, a large number of new cases of consequence were detected and put on MDT. An extensive nationwide media campaign and IEC activities is expected to have a long-term impact. Thus, NLEC has contributed substantially towards achieving the leprosy elimination goal in Bangladesh. 